\title{
THE INTERACTION BETWEEN SELECTED ANTIDEPRESSANTS AND ZINC OXIDE NANOPARTICLES
}

\author{
${ }^{1}$ Roman MARŠÁLEK, ${ }^{1}$ Martin ŠVIDRNOCH \\ ${ }^{1}$ University of Ostrava, Ostrava, Czech Republic, EU, roman.marsalek@osu.cz
}

https://doi.org/10.37904/nanocon.2020.3737

\begin{abstract}
Interactions between tricyclic antidepressants and zinc oxide nanoparticles have been studied. Amitriptyline and nortriptyline, which were immobilized from buffer medium at $37^{\circ} \mathrm{C}$, were selected as models. The key factor influencing the adsorption of these substances on zinc oxide is $\mathrm{pH}$. During the adsorption, an acid-base equilibrium was established between the buffer, zinc oxide and the antidepressant. These $\mathrm{pH}$ changes were also reflected in the surface charge of the adsorbent and the values of the zeta potential, which was also monitored. Both substances have a similar structure, yet they differ in their acid-base properties and also in their ability to form micelles. These different properties caused different values of the amount adsorbed on the surface of the zinc oxide. Adsorption isotherms show a sigmoidal course. The highest adsorbed amount of amitriptyline on $\mathrm{ZnO}$ is $6.38 \mathrm{mmol} \mathrm{g}^{-1}$, in the case of nortriptyline it is $3.68 \mathrm{mmol} \mathrm{g}^{-1}$. The adsorption is directed in accordance with the pseudo-second-order kinetic equation. The values from the kinetic equations, as well as the changes in the zeta potential, indicate different mechanisms of immobilization of amitriptyline and nortriptyline on the surface of zinc oxide nanoparticles. In the case of both substances, due to the interaction with zinc oxide, they were significantly removed from the liquid medium; in the case of amitriptyline, the residual concentration was less than $10 \%$ at an initial concentration of $5 \mathrm{mmol} \mathrm{L}^{-1}$.
\end{abstract}

Keywords: Antidepressants, $\mathrm{ZnO}$ nanoparticles, adsorption, zeta potential

\section{INTRODUCTION}

With the growing production and use of pharmaceuticals, their release into the environment increases. In Western civilizations, the use of medicines is steadily growing. This increase applies to all classes of drugs, including significant antibiotics, analgesics, antidepressants and many others. In the United States of America, or in some Scandinavian countries, up to 100 people in every 1,000 people use antidepressants. Tricyclic antidepressants are partially trapped by activated sludge in wastewater treatment plants. However, some of these substances enter the watercourses; they are not readily hydrolysed and are also not biodegraded [1]. In addition to the environmental burden mentioned above, there is another risk associated with the use of antidepressants. The risk of poisoning can be very critical especially in the case of children [2]. Possibilities to remove antidepressants from the body in case of overdose are being studied. An example may be a study using a mixture of liposomes, proteins and serum [3]. The aim is therefore to remove pharmaceutical substances from the environment in which they are harmful. One possibility that is widely examined is adsorption. Adsorption can be used to remove toxic substances from water sources, but also from human digestive tract.

In the case of adsorption reviews, scientists are mainly concerned with adsorption materials, adsorption conditions and the mechanism of adsorption. A variety of adsorbents are investigated for pharmaceuticals adsorption, such as: carbonaceous materials, clay minerals, polymers, silica based materials, and other various adsorbents. In addition to synthetic adsorbents, so-called cheap adsorbents are studied for economic reasons $[4,5]$. These review articles summarize the adsorption capacity of sorbents for individual drugs. The 
authors also discuss in detail the factors that influence the adsorption process, the kinetics and thermodynamics of adsorption. Another review article deals with the flow adsorption of pharmaceuticals contaminants on various materials [6].

One group of adsorbents are metal oxides, in which photocatalytic properties are studied in addition to adsorption activity. A mixture of titanium oxide and silicon oxide was used to remove paracetamol and ibuprofen from the liquid medium [7]. Heterojunction zinc tin oxide $\left(\mathrm{ZnO} / \mathrm{SnO}_{2}\right)$ was used for photodegradation of amytriptyline. The material was prepared as nanoparticles [8]. Core-shell nanoparticles of the type $\mathrm{Fe}_{3} \mathrm{O}_{4} @ \mathrm{ZrO}_{2} @ \mathrm{~N}$ - cetylpyridinium were used for solid phase extraction of antidepressant drugs amitriptyline and nortriptyline from plasma [9]. The nanoparticles of magnetic surface molecular imprinted polymer mesoparticles $\left(\mathrm{Fe}_{3} \mathrm{O}_{4} @ \mathrm{SiO}_{2}-\mathrm{MIP}\right)$ were studied as a selective adsorbent for amitriptyline in biological samples [10]. Six antidepressants were adsorbed on silver nanoparticles and the mechanism of adsorption was compared with the interaction between antidepressants and receptors [11].

The aim of this work is to characterize the adsorption of amitriptyline and nortriptyline on zinc oxide nanoparticles. The kinetics of adsorption, adsorption capacity of materials, change of surface charge and mainly influence of $\mathrm{pH}$ were studied. The possible mechanism of the adsorption of amitriptyline and nortriptyline has been suggested.

\section{EXPERIMENTAL PART}

\subsection{Materials and methods}

The amitryptiline (AMIT) and the nortriptyline (NORT) used were in an $\mathrm{HCl}$ forms which are freely soluble in water, a pKa value of AMIT is 9.4 and 9.7 for NORT, respectively. They were purchased from Sigma Aldrich, USA. Nanoparticle oxide $\mathrm{ZnO}$ was used as the commercial product purchased from Sigma Aldrich, USA. The size of particles was under 100nm. Phosphate buffered saline tablets (Sigma Aldrich, USA) were used for solution preparation of $\mathrm{pH}$ 7.4. All other used chemicals were of the highest purity grade available from commercial sources. The zeta potential of all suspensions was measured using the Zetasizer Nano ZS (Malvern Instruments Ltd., GB). Before zeta potential was measured all samples were sonicated for 5 minutes

\subsection{Adsorption experiments}

The basic design, which was the same for all adsorption experiments, was as follows: solution volume $5 \mathrm{ml}$, $\mathrm{pH} 7.4$, adsorbent weight $5 \mathrm{mg}$, shaken in a bath at $37^{\circ} \mathrm{C}$. The contact time was 24 hours, except for the measurement of adsorption kinetics. After the contact time, the solutions were centrifuged and filtered through a syringe filter. The resulting antidepressants concentration was determined by UV-VIS spectrophotometry. Amitriptyline and nortriptyline as well as exhibit a maximum absorbance at $239 \mathrm{~nm}$. All experiments were performed at least three times.

In the case of kinetic experiments, it was performed as follows. The initial antidepressants concentration was $10 \mathrm{mmol} / \mathrm{L}$. Samples were taken and analysed at specified time intervals. A total of 7 samples were prepared in flasks, one for each time sampling. Thus, samples were not taken sequentially from a single flask, thus reducing the volume in the flask and changing the ratio between the liquid and solid phases. The pseudo-firstorder and pseudo-second-order kinetic models are most commonly used to describe the rate of adsorption $[12,13]$.

The maximum of adsorption capacity for our adsorption materials was evaluated from adsorption isotherms. Isotherms show how the adsorbed amount depends on the equilibrium concentration. The initial concentration of AMIT and NORT ranged from $0.1 \mathrm{mmol} \mathrm{L}^{-1}$ to $10 \mathrm{mmol} \mathrm{L}^{-1}$. After the contact time (24 hours), the samples were analysed as described above. The amount of antidepressant adsorbed (a) was determined from the change in the solution concentration before and after equilibrium, according to: 
$a=\frac{\left(c_{0}-c_{e}\right) \cdot V}{m}$

where:
a - the adsorbed amount $\left(\mathrm{mmol} \mathrm{g}^{-1}\right)$
$c_{0}$ - the initial concentration of AMIT (NORT) solution ( $\mathrm{mmol} \mathrm{L}^{-1}$ )
$c_{0}$ - the concentration of AMIT (NORT) solution at the adsorption equilibrium (mmol L-1)
$V$ - the volume of solution (ml)
$m$ - the mass of $\mathrm{ZnO}(\mathrm{mg})$

\section{RESULTS AND DISSCUSIONS}

The key factor that will affect the interactions between zinc oxide nanoparticles and the antidepressant will be $\mathrm{pH}$. PBS buffer was chosen from previous studies and according to literature sources. It is a commonly used buffer simulating a physiological environment with a $\mathrm{pH}$ value around 7.4. The traditional composition of PBS buffer is: $\mathrm{NaCl}, \mathrm{KCl}, \mathrm{NaH}_{2} \mathrm{PO}_{4}$ and $\mathrm{KH}_{2} \mathrm{PO}_{4}$. The material chosen for the immobilization of amitriptyline and nortriptyline is zinc oxide. Its solubility in water is relatively low, yet studies are known to document the effect of zinc oxide on $\mathrm{pH}$ [14]. This effect is further supported by possible reactions between $\mathrm{ZnO}$ dissociation products and compounds contained in the buffer, especially with phosphates. The following reactions can take place in the system:

$\mathrm{ZnO}+\mathrm{H}_{2} \mathrm{O} \leftrightarrow \mathrm{Zn}^{2+}+2 \mathrm{OH}^{-}$

The formation of hydroxide anions alone will lead to an increase in $\mathrm{pH}$. However, in the presence of a buffer, this effect should be suppressed. Zinc cations then react with phosphates to form various forms of complex particles.

$\mathrm{ZnO}+\mathrm{H}_{2} \mathrm{PO}_{4}^{-} \leftrightarrow \mathrm{ZnHPO}_{4}+\mathrm{OH}^{-}$

$\mathrm{Zn}^{2+}+\mathrm{H}_{2} \mathrm{PO}_{4}^{-} \leftrightarrow \mathrm{Zn}\left(\mathrm{H}_{2} \mathrm{PO}_{4}\right)_{2}$

In addition to raising the $\mathrm{pH}$, phosphates will also precipitate, forming flakes that are larger in size than the original zinc oxide. These agglomerates will also include antidepressant molecules, which are also present in solution. The instability of zinc oxide in an aqueous environment is also described by other authors [15]. To understand the interactions between the solid phase and the antidepressant molecules, the charge of these substances at a given $\mathrm{pH}$ is important. The $\mathrm{pH}$ dependence of zinc oxide is shown in Figure 1.

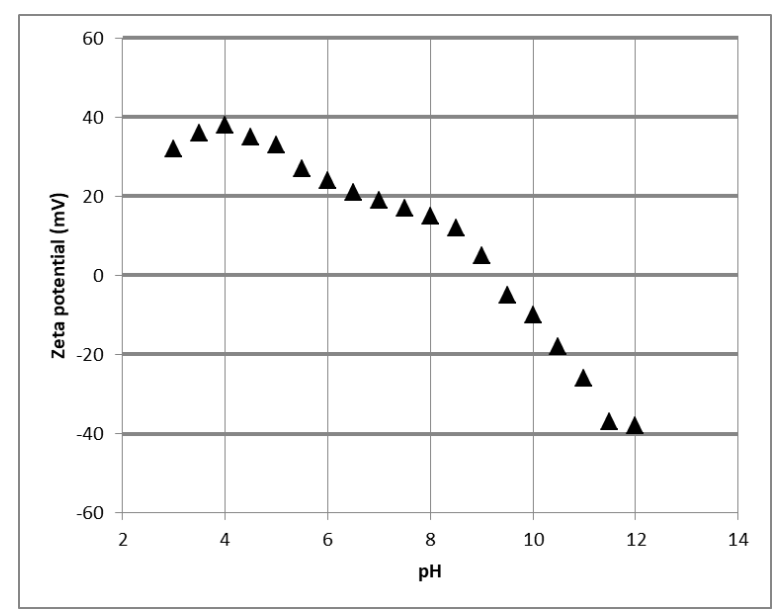

Figure 1 The influence of $\mathrm{pH}$ on zeta potential of $\mathrm{ZnO}$ 
On the curve of the dependence of the zeta potential on $\mathrm{pH}$, the point at which the value of the zeta potential is zero is particularly important. This is the so-called isoelectric point. The $\mathrm{pH}$ value at which the zeta potential of the zinc oxide particles is zero is around $\mathrm{pH}$ 9. In the case of zinc oxide, the isoelectric point value depends on the form in which it is present, the amount of impurities, etc. In general, two $\mathrm{pH}$ values are given for zinc oxide, in which the charge is zero. One $\mathrm{pH}$ is around $\mathrm{pH} 4-5$, the other around $\mathrm{pH} 9-10$ [16-18]. Due to the fact that the immobilization took place at a pH higher than seven, this weakly basic environment is especially important.

When nano-sized zinc oxide was added to the buffer, the $\mathrm{pH}$ shifted to about $\mathrm{pH} 10$ in accordance with the above equations (2-4). According to Figure 1, at this $\mathrm{pH}$, the zeta value of the zinc oxide potential is about $15 \mathrm{mV}$. Thus, the surface of the particles is negatively charged and should preferably attract positively charged particles. The antidepressants used, i.e. amitriptyline and nortriptyline, are tricyclic compounds which have a nitrogen atom in their aliphatic part of the molecule. The only difference in their molecules is on this nitrogen. In the case of amitryptyline, two methyl groups are attached, in the case of nortryptyline, there is one methyl group and one hydrogen. The $\mathrm{pK}_{\mathrm{A}}$ values found in the literature are for amitriptyline 9.4 and for nortryptyline 9.7 [19]. According to this criterion, amitriptyline is a slightly stronger acid. However, both of these substances will be in solution in different forms according to the actual $\mathrm{pH}$. In Figure 2, these forms are shown for nortryptyline.<smiles>CNCCC=C1c2ccccc2CCc2ccccc21</smiles><smiles>CNCCC=C1c2ccccc2CCc2ccccc21</smiles><smiles>N/C=C\C=C1c2ccccc2CCc2ccccc21</smiles>

Figure 2 Forms of neutral molecule and ions of nortryptyline

Although both antidepressants can be considered as weak acids, their pH dropped after their addition to the solution, depending on their concentration. In summary, it can be recalled that the initial pH of the PBS buffer was 7.4, increased to 10 after the addition of zinc oxide and then decreased again in the presence of antidepressants. Next Figure 3 shows the dependence of the adsorbed amount of antidepressant on the equilibrium concentration.

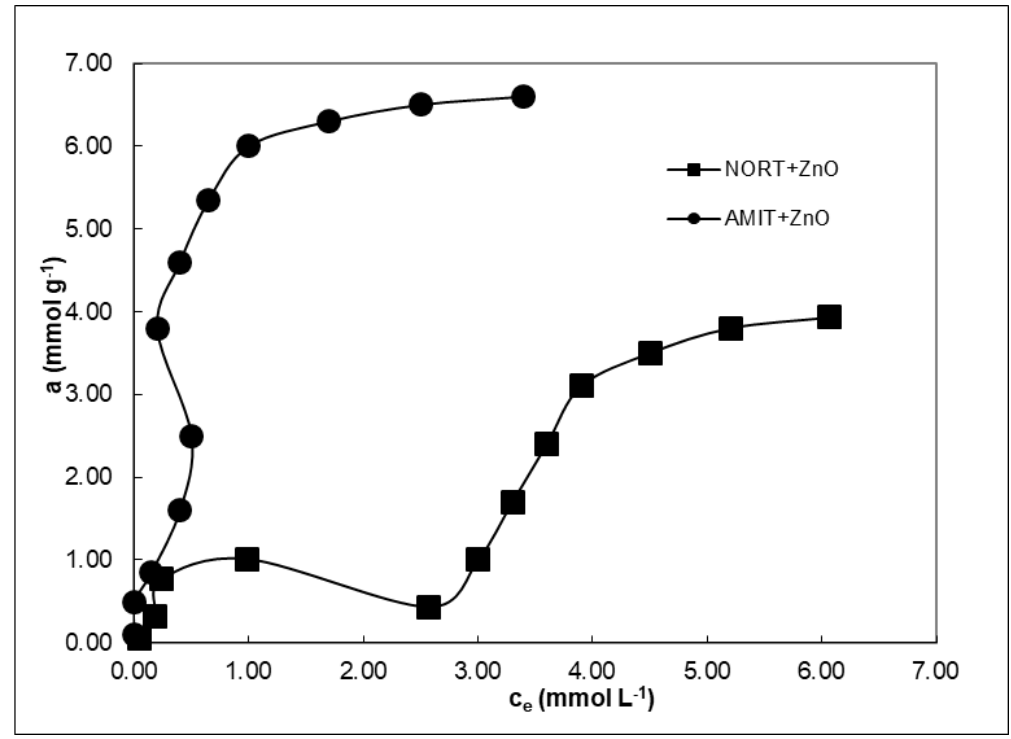

Figure 3 Adsorption isotherms of nortryptyline and amitryptyline on $\mathrm{ZnO}$ 
The adsorption isotherms of amitriptyline and nortriptyline have a sigmoidal character, which is evident especially in the adsorption of nortryptyline. At an initial nortriptyline concentration of up to $2 \mathrm{mmol} \mathrm{L}^{-1}$, the amount adsorbed increases. The $\mathrm{pH}$ was measured continuously and for these low concentrations of nortriptyline the $\mathrm{pH}$ was about 10 . At this $\mathrm{pH}$, the zeta potential of zinc oxide is negative and, conversely, nortriptyline occurs in solution in the form of a cation. From an initial concentration of $3 \mathrm{mmol} \mathrm{L}^{-1}$, the pH decreases due to deprotonation of the nortriptyline molecule. The $\mathrm{pH}$ takes values around 9 , which is the value of the isoelectric point of the zinc oxide used. The nortriptyline molecule has a neutral character; there is a relative decrease in the amount adsorbed. As the antidepressant concentration is further increased, the $\mathrm{pH}$ of the solution continues to decrease. The zeta potential of zinc oxide becomes positive, the nortriptyline molecule is negatively charged and adsorption increases again. The maximum adsorbed amount of nortriptyline is about $6.4 \mathrm{mmol} \mathrm{g}^{-1}$, in the case of nortriptyline this value is about $3.9 \mathrm{mmol} \mathrm{g}^{-1}$. These are relatively high values, which are probably caused not only by adsorption, but also by the precipitation of zinc oxide with the buffer components and the subsequent immobilization of antidepressants inside the formed precipitates. The almost double adsorption capacity for amitriptyline compared to nortriptyline can be explained by micelle formation. Both substances form micelles in a high ionic strength environment. The critical micellar concentration is lower in the case of nortriptyline, in other words the substance also occurs in solution in the form of micelles, the ability of which is less trapped on the surface of zinc oxide.

A comparison of linearized shapes of kinetic models shows that the adsorption of antidepressants on zinc oxide nanoparticles corresponds better to the second-order pseudo-kinetic equation. The estimated values of the adsorption amount correspond to the conclusions from the adsorption isotherms. The rate of equilibrium was approximately the same for both substances. Different kinetic parameters were found only in extreme cases of concentrations. By this is meant the concentration of substances which has led to a change in the pH of the solution, to the reaching of an isoelectric point and thus to a decrease in the amount adsorbed.

\section{CONCLUSION}

The oxide nanoparticles have a high affinity for tricyclic antidepressants. Adsorption on the surface of zinc oxide nanoparticles together with precipitation led to the removal of amitriptyline and nortriptyline from the PBS buffer medium. The most important factor that affects the adsorption process is $\mathrm{pH}$. The removal of antidepressants from solution is not only controlled by simple adsorption, but is a complex of chemical-physical processes. However, the adsorption capacities found suggest the possible use of zinc oxide nanoparticles for the removal of tricyclic anti-depressants from liquid media. These properties could be used in wastewater treatment, but also in the removal of these substances from the body during unwanted poisoning.

\section{ACKNOWLEDGEMENTS}

This study was supported by the project of Faculty of Science, University of Ostrava, No. SGS08/PřF/2020. Authors thank bc. Jakub Malota (Department of chemistry, Faculty of Science, University of Ostrava) for the measurement of antidepressants concentration.

\section{REFERENCES}

[1] CHOI, J.-W., YUFENG, Z., BEDIAKO, J.K., CHO, Ch.-W, YUN, Y.-S. Estimating environmental fate of tricyclic antidepressants in wastewater treatment plant. Science of The Total Environment. 2018, vol. 634, pp. 52-58.

[2] KERR, G., MCGUFFIE, A. WILKIE, S. Tricyclic antidepressant overdose: a review. Emergency Medicine Journal: EMJ. 2001, vol. 18, no. 4, pp. 236-241.

[3] HOWELL, B.,CHAUHAN, A.. Uptake of amitriptyline and nortriptyline with liposomes, proteins, and serum: Implications for drug detoxification. Journal of Colloid and Interface Science. 2008, vol. 319, no. 1, pp. 81-93.

[4] AKHTAR, J., AMIN, N.A.S., SHAHZAD, K. A review on removal of pharmaceuticals from water by adsorption. Desalination and Water Treatment. 2016, vol. 57, no. 27, pp. 12842-12860. 
[5] DE ANDRADE, J.M., OLIVEIRA, F., DA SILVA, M.G.C., VIEIRA, M.G.A. Adsorption of Pharmaceuticals from Water and Wastewater Using Nonconventional Low-Cost Materials: A Review. Industrial \& Engineering Chemistry Research. 2018, vol. 57, no. 9, pp.3103-3127.

[6] AHMED, M.J., HAMEED, B.H. Removal of emerging pharmaceutical contaminants by adsorption in a fixed-bed column: A review. Ecotoxicology and Environmental Safety. 2018, vol. 149, pp. 257-266.

[7] CIESIELCZYK, F., GOSCIANSKA, J., ZDARTA,J., JESIONOWSKI, T. The development of zirconia/silica hybrids for the adsorption and controlled release of active pharmaceutical ingredients. Colloids and Surfaces $A$ :

Physicochemical and Engineering Aspects. 2018, vol. 545, pp. 39-50.

[8] IVETIĆ, T.B., FINČUR, N.L., ABRAMOVIĆ, B.F, DIMITRIEVSKA, M., ŠTRBAC, G.R., ČAJKO, K.O., MILJEVIĆ, B.B., ĐAČANIN, Lj.R., LUKIĆ-PETROVIĆ, S.R. Environmentally friendly photoactive heterojunction zinc tin oxide nanoparticles. Ceramics International. 2016, vol. 42, no. 2, pp. 3575-3583.

[9] ZARE, F., GHAEDI, M. DANESHFAR, A.. Solid phase extraction of antidepressant drugs amitriptyline and nortriptyline from plasma samples using core-shell nanoparticles of the type Fe3O4@ZrO2@N- cetylpyridinium, and their subsequent determination by HPLC with UV detection. Microchimica Acta. 2015, vol. 182, no. 1-12, pp. 1893-1902.

[10] KAMARI, K., TAHERI, A.. Preparation and evaluation of magnetic core-shell mesoporous molecularly imprinted polymers for selective adsorption of amitriptyline in biological samples. Journal of the Taiwan Institute of Chemical Engineers. 2018, vol. 86, pp. 230-239.

[11] JAWORSKA, A., MALEK, K. A comparison between adsorption mechanism of tricyclic antidepressants on silver nanoparticles and binding modes on receptors. Surface-enhanced Raman spectroscopy studies. Journal of Colloid and Interface Science. 2014, vol. 431, pp. 117-124.

[12] LAGERGREN, S. Y. Zur Theorie der sogenannten Adsorption gelöster Stoffe. Kungliga Svenska Vetenskapsakademiens. Handlingar 1898, vol. 24, pp. 1-39.

[13] HO, Y. S., MCKAY, G. A comparison of chemisorption kinetic models applied to pollutant removal on various sorbents. Process Safety and Environmental Protection. 1998, pp. 332-340.

[14] MEISSNER, T., OELSCHLÄGEL, K. POTTHOFF, A.. Implications of the stability behavior of zinc oxide nanoparticles for toxicological studies. International Nano Letters. 2014, vol. 4, no. 3, pp 116.

[15] TSO, Ch., ZHUNG, Ch., SHIH, Y., TSENG, Y.-M., WU, S., DOONG, R. Stability of metal oxide nanoparticles in aqueous solutions. Water Science and Technology. 2010, vol. 61, no. 1, pp. 127-133.

[16] MOHD OMAR, F., ABDUL AZIZ, H., STOLL, S. Aggregation and disaggregation of ZnO nanoparticles: Influence of pH and adsorption of Suwannee River humic acid. Science of The Total Environment. 2014, vol. 468-469, pp. 195-201.

[17] MARSALEK, R. Particle Size and Zeta Potential of ZnO. APCBEE Procedia. 2014, vol. 9.

[18] GUSTAFSSON, J., NORDENSWAN, E., ROSENHOLM, J.B. Effect of pH on the sedimentation, z-potential, and rheology of anatase suspensions. Colloids and Surfaces A: Physicochemical and Engineering Aspects. 2003, vol. 212, pp 235-247.

[19] FLORENCE, A., ATTWOOD, D. Physicochemical principles of pharmacy. 4. ed., reprinted. London: Pharmaceutical Press, 2007, pp. 56-91. 